\title{
ADVANTAGES AND LOSSES ANALYSIS ON BURNING HOURS BY THE PRODUCTION PLANNING CONTROL IN DETERMINING TIME IMPLEMENTATION OF MAINTENANCE ACTIVITIES
}

\author{
Humaid Iswahyu Hafizh Rakha ${ }^{1}$, Fajar Khanif Rahmawati ${ }^{2}$ \\ ${ }^{1,2}$ Department of Aerospace Engineering - Institute Teknologi Dirgantara Adisutjipto \\ humaid.dika@gmail.com, fajar.khanif@,gmail.com
}

\begin{abstract}
Burning Hours is the one of policy in scheduling aircraft maintenance. With the burning hours the operator could performed aircraft maintenance before the due time. Burning Hours is indeed beneficial for flight operators to maintain the stability of the safety of the aircraft operation. Using the quantitative analysis method with the sample data's from two aircraft, found that the burning hours affects to Burning Hours Cost loss for every aircraft meintenance activity. The value of Burning Hours Cost Loss and Potential Lost per Day needs to be considered by operators in scheduling maintenance activities, because it is possible that Burning Hours cannot be avoided in aircraft operation. Based on the data processing, the value of burning hours cost lost is not more than limit of potential lost per day. However it should also be considered if burning hours applied continuously will increase maintenance cost. Therefore, between maintenance planning department and the operation department should keep good coordination to minimize the burning hours cost loss.
\end{abstract}

Keywords: Planning, Maintenance, Burning Hours

\section{Pendahuluan}

Pelaksanaan perawatan pesawat yang telah ditentukan dalam Maintenance Program merupakan salah satu konsekuensi dari pemakaian jam terbang pesawat selama beroperasi. Dalam menentukan rencana pelaksanaan perawatan pesawat mempertimbangkan beberapa aspek yang sangat berpengaruh diantaranya adalah dari aspek keamanan dan aspek finansial. Kegiatan operasional pesawat yang sering kali berada di tempat yang tidak memiliki capability untuk melaksanakan kegiatan perawatan pesawat, maka pelaksanaan perawatan dilakukan lebih awal dari waktu jatuh temponya. Keputusan ini memberikan kelebihan dari segi keamanan pesawat terbang, tetapi jika dilihat dari aspek finansial maka pelaksanaan perawatan terjadwal secara lebih awal dari waktunya yang seharusnya akan mengakibatkan pertambahan biaya yang membebani perusahaan.

Beberapa alasan yang medukung adanya pertambahan biaya tersebut antara lain adalah waktu yang masih tersisa antara pelaksanaan hingga jatuh tempo perawatan dapat dimanfaatkan untuk kegiatan operasional. Selain itu dalam kegiatan perawatan yang melibatkan didalamnya penggantian komponen, maka sangat besar kemungkinan bahwa komponen yang dilakukan penggantian dengan waktu lebih awal tersebut masih laik dan tidak perlu diganti, sehingga dapat menghemat dari segi finansial.

Waktu pelaksanaan perawatan merupakan faktor penting dalam memilih service center, karena tidak tersedianya pesawat dapat menimbulkan biaya yang tinggi bagi pelanggan [6]. Maka strategi dalam mengatur jadwal pelaksanaan perawatan pesawat sangatlah penting. Armada pesawat terbang tidak hanya dituntut untuk selalu serviceable ketika akan dioperasikan tetapi kegiatan perawatan harus dilaksanakan sebaik mungkin. Hal ini 
dikarenakan kegiatan perawatan juga termasuk dari bagian dalam pelayanan terhadap pengguna jasa penerbangan. Bagi pengguna jasa penerbangan, keamanan armada yang digunakan merupakan faktor yang utama. Maka bagi setiap operator harus dapat memberikan jaminan bahwa pelaksanaan kegiatan perawatan armadanya telah memperhatikan aspek keamanan. Menurut Rigas Doganis, kebijakan itu harus ditetapkan untuk menarik dan memuaskan pelanggan potensial di segmen pasar yang berbeda yang telah diidentifikasi [1]. Karena beberapa kelompok pelanggan akan rela membayar harga tiket pesawat yang lebih mahal untuk dapat memperoleh jaminan dari aspek kemanan pesawat terbang.

Rigas Doganis pada bukunya yang berjudul "Flying Off Course: Airline Economics and Marketing (Fourth Edition) - 2010" menjelaskan bahwa Product Planning adalah tentang pengambilan keputusan terhadap bagaimana produk dan servis yang diberikan oleh perusahaan maskapai penerbangan di setiap pasarnya [1]. Dalam perawatan pesawat terdapat istilah burning hours. Burning hours merupakan istilah yang mengacu kepada ketidaksesuaian antara jadwal perawatan pesawat secara teori dan pelaksanaan perawatan pesawat yang dilakukan. Ketidaksesuaian ini merupakan hasil dari pertimbangan beberapa aspek yang salah satu nya dari sisi operasional yaitu penggunaan pesawat untuk kegiatan operasional.

Berdasarkan hasil wawancara dengan praktisi PPC (Planning Production and Control), burning hours adalah jam terbang yang tidak dipakai oleh operator untuk mengoperasikan pesawat dikarenakan jadwal perawatan yang dimajukan dengan berbagai pertimbangan. Melaksanakan kegiatan perawatan lebih awal dari jadwal seharusnya merupakan upaya untuk menyeimbangkan antara penggunaan rutin pesawat dengan aturan perawatan yang yang telah ditetapkan.

\section{Metode Penelitian}

Proses penelitian yang dilakukan adalah sebagai berikut:

a. Melakukan pengambilan data dari dokumen AFML dan MPD pada pesawat DHC6400 Twin Otter untuk mengetahui kegiatan perawatan pesawat yang dilakukan serta jadwal pelaksanaan kegiatan perawatan [4] [5].

b. Melakukan filter data dari dokumen tersebut untuk menghitung selisih jam terbang antara interval yang telah ditentukan oleh manufaktur dengan jadwal actual pelaksanaan kegiatan perawatan.

c. Menghitung efisiensi dari penggunaan jam terbang pesawat sebelum dilakukannya kegiatan perawatan dari jadwal terakhir kegiatan perawatan.

d. Menetapkan burning hours yang ada dari hasil perhitungan untuk menganalisa biaya pendapatan yang seharusnya bisa didapatkan oleh operator.

\section{a. Pengambilan Data}

Data yang digunakan adalah laporan perawatan dari dua pesawat DHC 6-300 Twin Otter [4]. Terkait dengan kebijakan dari narasumber terhadap data yang dipakai, maka nomor registrasi pesawat disamarkan dengan tidak mengubah data asli yang digunakan dalam pengolahan data. Selanjutnya, nomor registrasi yang digunakan adalah PK-ABS dan PK-ABG.

Masing-masing pesawat memiliki utilisasi penerbangan yang hampir sama dan melakukan penerbangan jarak dekat untuk daerah-daerah pedalaman Indonesia Timur. Dikarenakan penggunaan yang selalu jauh dari fasilitas heavy maintenance, maka perlu dilakukannya penjadwalan perawatan yang disiapkan jauh-jauh hari dari tanggal jatuh tempo, agar utilisasi pesawat tidak melebihi batas jatuh tempo untuk perawatan. 
Data yang digunakan dalam penelitian ini merupakan laporan kegiatan perawatan EMMA Inspection dimana interval pelaksanaannya adalah $125 \mathrm{FH}$ [5]. Perhitungan dan analisa yang dilakukan adalah menghitung burning hours serta dampaknya terhadap biaya dan pendapatan operator. Adapun metode yang digunakan adalah metode analisis kuantitatif dengan mengolah data yang telah didapatkan dari narasumber [3]. Data riwayat pelaksanaan EMMA Inspection dengan interval 125FH selama periode 2015 sampai dengan 2019 sebagaimana tabel 1 dan tabel 2.

Table 1 Data PK-ABS

\begin{tabular}{|c|c|c|c|c|}
\hline \multirow{2}{*}{ Record } & Data Ke & Interval & Performed & $\begin{array}{c}\text { Next } \\
\text { Due }\end{array}$ \\
\cline { 2 - 5 } & i & D & Xi & \\
\hline Sep-15 & 1 & 125 & 39302 & 39427 \\
\hline Oct-15 & 2 & 125 & 39424 & 39549 \\
\hline Nov-15 & 3 & 125 & 39545 & 39670 \\
\hline Dec-15 & 4 & 125 & 39661 & 39786 \\
\hline Jan-16 & 5 & 125 & 39783 & 39908 \\
\hline Feb-16 & 6 & 125 & 39903 & 40028 \\
\hline Mar-16 & 7 & 125 & 40021 & 40146 \\
\hline Apr-16 & 8 & 125 & 40140 & 40265 \\
\hline May-16 & 9 & 125 & 40260 & 40385 \\
\hline Jun-16 & 10 & 125 & 40382 & 40507 \\
\hline Jul-16 & 11 & 125 & 40505 & 40630 \\
\hline Aug-16 & 12 & 125 & 40617 & 40742 \\
\hline Sep-16 & 13 & 125 & 40731 & 40856 \\
\hline Oct-16 & 14 & 125 & 40846 & 40971 \\
\hline
\end{tabular}

Table 2 Data PK-ABG

\begin{tabular}{|c|c|c|c|c|}
\hline \multirow{2}{*}{ Record } & Data Ke & Interval & Performed & $\begin{array}{c}\text { Next } \\
\text { Due }\end{array}$ \\
\cline { 2 - 5 } & $\mathbf{i}$ & $\mathbf{D}$ & $\mathbf{X i}$ & \\
\hline Oct-18 & 1 & 125 & 52138 & 52263 \\
\hline Nov-18 & 2 & 125 & 52261 & 52386 \\
\hline Dec-18 & 3 & 125 & 52379 & 52504 \\
\hline Jan-19 & 4 & 125 & 52495 & 52620 \\
\hline Feb-19 & 5 & 125 & 52609 & 52734 \\
\hline Apr-19 & 6 & 125 & 52733 & 52858 \\
\hline May-19 & 7 & 125 & 52854 & 52979 \\
\hline Jun-19 & 8 & 125 & 52974 & 53099 \\
\hline Jul-19 & 9 & 125 & 53091 & 53216 \\
\hline Aug-19 & 10 & 125 & 53211 & 53336 \\
\hline Sep-19 & 11 & 125 & 53334 & 53459 \\
\hline Oct-19 & 12 & 125 & 53455 & 53580 \\
\hline Nov-19 & 13 & 125 & 53565 & 53690 \\
\hline Dec-19 & 14 & 125 & 53687 & 53812 \\
\hline
\end{tabular}

\section{b. Penghitungan}

Untuk mengetahui besarnya burning hours perlu dilakukan perhitngan flight hours (FH) actual atau actual utilization dari pelaksanaan perawatan pesawat terakhir dengan pelaksanaan sebelumnya. Sehingga nilai actual utilization dapat diketahui dari penghitungan selisih jam terbang pesawat saat kegiatan perawatan yang dilakukan dengan kegiatan perawatan sebelumnya. Dari penjelasan tersebut serta dari data tabel 1 dan 2, maka hal ini dapat dibuat persamaan 1: 


$$
\begin{array}{lll}
\text { Dimana: } & \text { (i) } & =\text { Urutan data ke-(i) } \\
\text { Di } & =\text { Actual Flight Hours (Actual Utilization) } \\
\text { X } & =\text { Actual Performed of maintenance }
\end{array}
$$

Setelah mengetahui actual utilization ini, penghitungan dilanjutkan untuk mengetahui besaran burning hours yang terjadi pada kegiatan perawatan tersebut. Secara garis besar, untuk menghitung burning hours adalah hasil penghitungan actual utilization dikurangi dengan interval dari standard EMMA Check yang berasal dari manufaktur yaitu 125FH. Dari perhitungan tersebut akan diperoleh flight hours yang sebetulnya masih bisa digunakan untuk pengoperasian pesawat, tetapi tidak digunakan karena akan kegiatan perawatan pesawat EMMA Check $125 \mathrm{FH}$ yang dilakukan lebih awal.

Melihat kembali pada persamaan 1, Di adalah actual utilization dari pesawat. Lalu pada table 1 dan 2, diketahui bahwa $D$ adalah interval yang telah ditentukan oleh pihak manufaktur terhadap kegiatan inspeksi pesawat. Dikarenakan untuk mencari berapakah jumlah waktu yang tidak terpakai dalam pengoperasian pesawat tersebut, maka dapat dibuat persamaan (2)

$$
B_{i}=D-D_{i}
$$

$\begin{aligned} \text { Dimana: } & \mathrm{B}=\text { Burning Hours } \\ & D=\text { Interval from manufacture } \\ & \text { Di }=\text { Actual Utilization pesawat diantara dua kegiatan perawatan }\end{aligned}$

Setelah melewati tahap penghitungan diatas, selanjutnya sejumlah data yang telah didapatkan mulai dianalisa untuk mengetahui dampak yang dapat ditimbulkan oleh burning hours tersebut. Hal pertama yang dilakukan dalam analisa ini adalah mengetahui terlebih dahulu total actual utilization dari pesawat dari data yang telah tersedia. Perhitungan total actual utilization ini adalah dengan menjumlahkan seluruh data pada kolom tabel $\mathrm{D}_{\mathrm{i}}$.

Dari perhitungan diperoleh PK-ABS total actual utilization selama 14 Bulan terhitung dari tanggal 20 September 2015 sampai dengan 20 Oktober 2016 adalah sebanyak $1544 \mathrm{FH}$. Sedangkan untuk PK-ABG total keseluruhan jam terbang selama 14 Bulan terhitung dari tanggal 10 Oktober 2018 sampai dengan 15 Desember 2019 adalah sebanyak $1549 \mathrm{FH}$. Dengan asumsi bahwa pesawat tersebut melakukan penerbangan selama kurun data pengamatan, maka total operasional day untuk PK-ABS adalah 396 hari, sedangkan untuk PK-ABG adalah 431 hari.

Setelah mengetahui total actual utilization, selanjutnya menghitung pemakaian rata-rata pesawat untuk kegiatan operasional dalam 1 hari atau utilization/day. Maka bisa didapatkan persamaan 3 untuk perhitungannya adalah:

$$
\text { Utilization }(\mathrm{FH} / \text { Day })=\frac{\text { Total Flight }}{\text { Total Day Utilized }}=\mathrm{U}
$$

Setelah mengetahui utilisasi pesawat perhari, maka langkah selanjutnya adalah menghitung biaya untuk kegiatan perawatan pesawat yang digunakan oleh operator. Berdasarkan data dari tempat penelitian, total operational cost yang dikeluarkan adalah $1.200 \mathrm{USD} / \mathrm{FH}$ untuk setiap pesawat dalam operasional satu jam terbang. total operational 
cost (TOC) terbagi menjadi beberapa bagian, salah satunya adalah maintenace cost. Salah satu komponen dalam maintenance cost adalah EMMA Cost $125 \mathrm{FH}$.

Berdasarkan data dari tempat penelitian maintenance cost adalah $30 \%$ dari TOC sedangkan untuk EMMA Cost adalah 15\% dari Maintenance Cost yang telah diperhitungkan. Sehingga dapat dibuat persamaan 4 dan 5:

$$
\begin{gathered}
\text { Maintenance Cost }=30 \% \times \text { TOC } \\
\text { EMMA Cost }(E C)=15 \% \times \text { Maintenance Cost }
\end{gathered}
$$

Setelah mengetahui rincian biaya terkait dengan kegiatan perawatan, maka langkah selanjutnya adalah menghitung biaya yang hilang ketika burning hours dilakukan oleh operator.

Burning Hours Cost Loss (BHL) adalah kerugian biaya saat jadwal kegiatan perawatan dimajukan atau ketika burning hours terjadi pada suatu jadwal kegiatan perawatan. Kerugian ini disebabkan oleh dimajukannya jadwal perawatan pesawat dari jatuh tempo seharusnya. Sehingga ddidapatkan persamaan 6:

$$
\begin{aligned}
& \text { Burning Hours Cost Loss }=B H L \\
& B H L=B \times E C
\end{aligned}
$$

Dalam pengoperasian pesawat setiap operator akan mendapatkan revenue atau pendapatan utuh yang belum dikurangi dengan Total Operational Cost, serta profit atau pendapatan bersih yang sudah dikurangi TOC [2]. Berdasarkan data dari tempat penelitian Average Revenue per FH (REV) dari operator adalah sebesar 1650 USD/FH. Sedangkan profit yang diterima adalah sebesar $450 \mathrm{USD} / \mathrm{FH}$. Data tersebut berlaku untuk pesawat PKABS maupun PK-ABG yang memiliki perhotungan pendapatan dan profit dengan pola hitungan yang sama sebagaimana pada persamaan 7 .

$$
\begin{aligned}
& \text { Average Revenue per FH }(U S D / F H)=R E V \\
& R E V=1650 U S D / F H
\end{aligned}
$$

Sedangkan untuk Profit operator dalam setiap satu jam terbang adalah:

$$
\begin{aligned}
& \text { Potential Profit per Flight }(U S D / F H)=P_{p} \\
& P_{p}=R E V-T O C \\
& P_{p}=1650 \mathrm{USD} / \mathrm{FH}-1200 \mathrm{USD} / \mathrm{FH} \\
& P_{p}=450 \mathrm{USD} / \mathrm{FH}
\end{aligned}
$$

Perhitungan pendapatan rata-rata dan profit operator perlu dilakukan dalam analisis ini agar operator dalam mengambil kebijakan burning hours tidak merugikan operasional penerbangan. Kerugian ini umumnya disebabkan oleh kesalahan penentuan jadwal pelaksanaan perawatan pesawat yang terlalu jauh dari jadwal seharusnya atau penjadwalan yang dilakukan di hari-hari operasional yang dianggap produktif. Kesalahan ini dapat berakibat pada kerugian operator penerbangan terutama pada masalah keuangan, dimana pada hari atau sisa jam terbang tersebut seharusnya pesawat dapat beroperasi, akan tetapi harus grounded di hangar untuk pelaksanaan kegiatan perawatan pesawat. Serta kesalahan dalam memperhitungkan utilisasi dan rute penerbangan, sehingga pada waktu jatuh tempo, pesawat yang seharusnya berada pada pusat perawatan tetapi pesawat justru berada pada lokasi yang jauh dari home base maintenance operator untuk melakukan perawatan. 
Oleh karena itu, diperlukan batasan untuk pengambilan kebijakan burning hours pada jadwal perawatan pesawat. Batasan ini adalah kerugian biaya jika pesawat tersebut nantinya harus grounded selama satu hari terutama jika satu hari tersebut merupakan hari operasional pesawat. Persamaan yang dibutuhkan untuk batasan ini adalah:

$$
\text { Potential Lost per Day }(U S D / D a y)=P L D
$$

$$
P L D=U \times P_{p}
$$

\section{Hasil dan Analisis}

Dari analisis data yang telah dilakukan, didapatkan hasil analisis berupa total burning hours yang dilakukan oleh operator untuk masing-masing pesawat adalah $81 \mathrm{FH}$ untuk pesawat PK-ABS dan 76 FH untuk PK-ABG. Serta total kerugian biaya dikarenakan burning hours atau Burning Hours Cost Loss (BHL) dari masing - masing pesawat sebesar 4374 USD untuk PK-ABS, sedangkan untuk pesawat PK-ABG sebesar 4104 USD. Namun, masing-masing BHL dari pesawat tidak melewati batas kerugian dari perhitungan operator atau disebut PLD, dimana untuk PLD dari pesawat PK-ABS sebesar 1755 USD/Day dan PLD untuk pesawat PK-ABG sebesar 1620 USD/Day. Hasil perhitungan dapat dilihat pada tabel 3 dan 4.

\begin{tabular}{|c|c|c|c|c|c|c|c|c|}
\hline \multirow[t]{2}{*}{ Record } & \multirow{2}{*}{$\begin{array}{c}\text { Data Ke } \\
\text { i }\end{array}$} & \multirow{2}{*}{$\begin{array}{c}\text { Interval } \\
\text { D }\end{array}$} & \multirow{2}{*}{\begin{tabular}{c|} 
Performed \\
$\mathrm{Xi}$ \\
\end{tabular}} & \multirow[t]{2}{*}{$\begin{array}{l}\text { Next } \\
\text { Due }\end{array}$} & \multirow{2}{*}{$\begin{array}{c}\begin{array}{c}\text { Actual } \\
\text { Utilization }\end{array} \\
\mathbf{D i}=\mathbf{X i}-(\mathbf{X i} \mathbf{i}-1) \\
\end{array}$} & \multirow{2}{*}{$\begin{array}{c}\begin{array}{c}\text { Burning } \\
\text { Hours (FH) }\end{array} \\
\text { B = D-Di }\end{array}$} & $\begin{array}{l}\text { Burning Hours } \\
\text { Cost Loss (USD) }\end{array}$ & $\begin{array}{l}\text { Potential Loss } \\
\text { Per Day (USD) }\end{array}$ \\
\hline & & & & & & & $\mathrm{BHL}=\mathrm{B} \times \mathrm{EC}$ & PLD \\
\hline Sep-15 & 1 & 125 & 39302 & 39427 & & & & \\
\hline Oct-15 & 2 & 125 & 39424 & 39549 & 122 & 3 & 162.00 & $\begin{array}{ll}\text { USD } & 1,755.00\end{array}$ \\
\hline Nov-15 & 3 & 125 & 39545 & 39670 & 121 & 4 & 216.00 & USD $1,755.00$ \\
\hline Dec-15 & 4 & 125 & 39661 & 39786 & 116 & 9 & 486.00 & USD $1,755.00$ \\
\hline Jan-16 & 5 & 125 & 39783 & 39908 & 122 & 3 & 162.00 & USD $1,755.00$ \\
\hline Feb-16 & 6 & 125 & 39903 & 40028 & 120 & 5 & 270.00 & USD $1,755.00$ \\
\hline Mar-16 & 7 & 125 & 40021 & 40146 & 118 & 7 & 378.00 & USD $1,755.00$ \\
\hline Apr-16 & 8 & 125 & 40140 & 40265 & 119 & 6 & 324.00 & $\begin{array}{ll}\text { USD } & 1,755.00\end{array}$ \\
\hline May-16 & 9 & 125 & 40260 & 40385 & 120 & 5 & 270.00 & $\begin{array}{ll}\text { USD } & 1,755.00\end{array}$ \\
\hline Jun-16 & 10 & 125 & 40382 & 40507 & 122 & 3 & 162.00 & $\begin{array}{ll}\text { USD } & 1,755.00 \\
\end{array}$ \\
\hline Jul-16 & 11 & 125 & 40505 & 40630 & 123 & 2 & 108.00 & USD $1,755.00$ \\
\hline Aug-16 & 12 & 125 & 40617 & 40742 & 112 & 13 & 702.00 & $\begin{array}{ll}\text { USD } & 1,755.00\end{array}$ \\
\hline Sep-16 & 13 & 125 & 40731 & 40856 & 114 & 11 & 594.00 & USD $1,755.00$ \\
\hline Oct-16 & 14 & 125 & 40846 & 40971 & 115 & 10 & USD $\quad 540.00$ & USD $1,755.00$ \\
\hline & & & & & Total $=$ & 81 & USD $4,374.00$ & \\
\hline
\end{tabular}

Table 3. Hasil Penghitungan PK-ABS

Table 4. Hasil Penghitungan PK-ABG

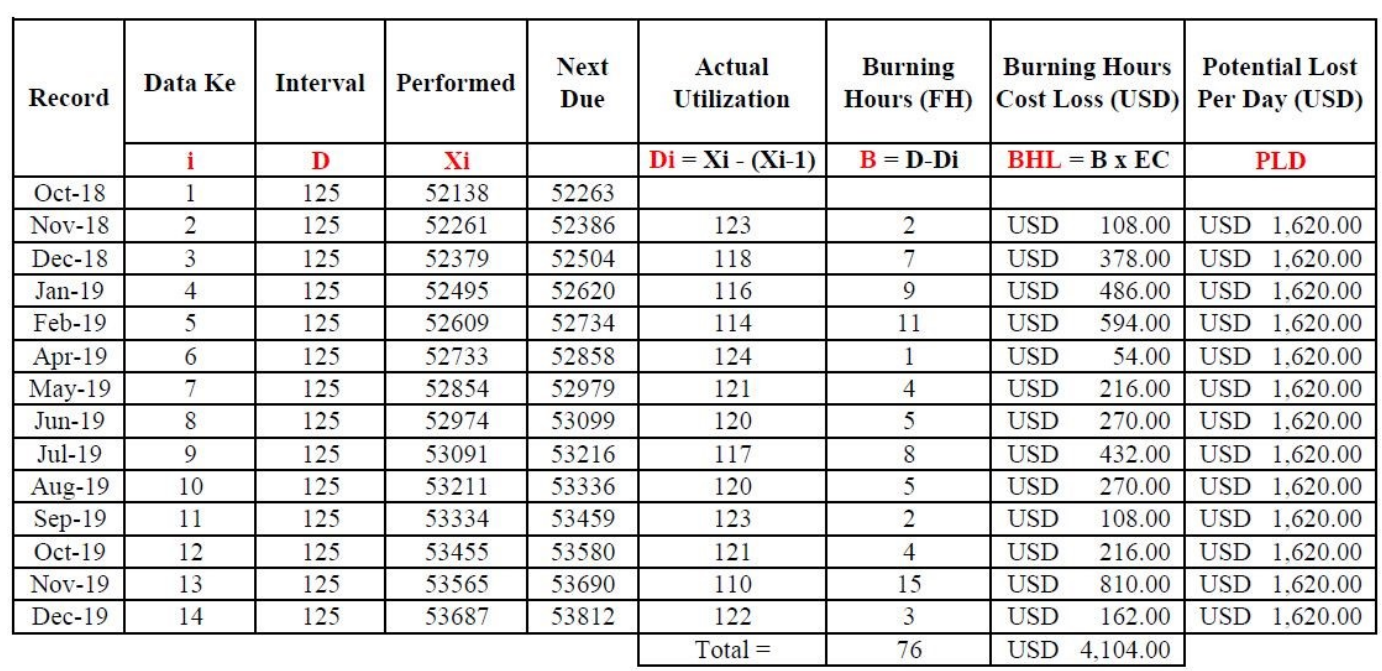


Burning Hours Cost Loss dari masing-masing pesawat diatas merupakan kerugian dari nilai investasi dari burning hours dengan biaya perawatannya yang telah dikeluarkan oleh perusahaan untuk kegiatan perawatan EMMA Check 125FH. Oleh karena itu untuk mengantisipasi adanya kerugian dalam dalam kegiatan operasional antara pemilik pesawat dengan pihak penyewa apabila pesawat harus grounded sementara waktu untuk kegiatan perawatan, maka jadwal perawatan dilakukan lebih awal sebelum waktu kontrak kerja dimulai. Pada satu sisi, ini merupakan keuntungan bagi pihak penyewa pesawat dan pihak penyedia pesawat dikarenakan safety dan airworthy pesawat tetap terjaga. Namun, bagi pihak penyedia pesawat akan mengalami kerugian dari sisi biaya, karena investasi biaya perawatan sebelumnya harus terbuang dan tidak terpakai secara optimal karena harus masuk maintenance facility kembali untuk perawatan pesawat dengan rincian biaya yang tidak jauh berbeda dengan kegiatan perawatan sebelumnya. Potential Lost per Day yang telah dikalkulasikan sebagai batasan untuk penetapan angka burning hours sangat berpengaruh dalam perencanaan ini. Sebagaimana pada gambar 1 dan 2 ditampilkan bahwa hasil dari penelitian ini, pengambilan keputusan burning hours cost loss tidak melebihi PLD yang akan dialami oleh operator.

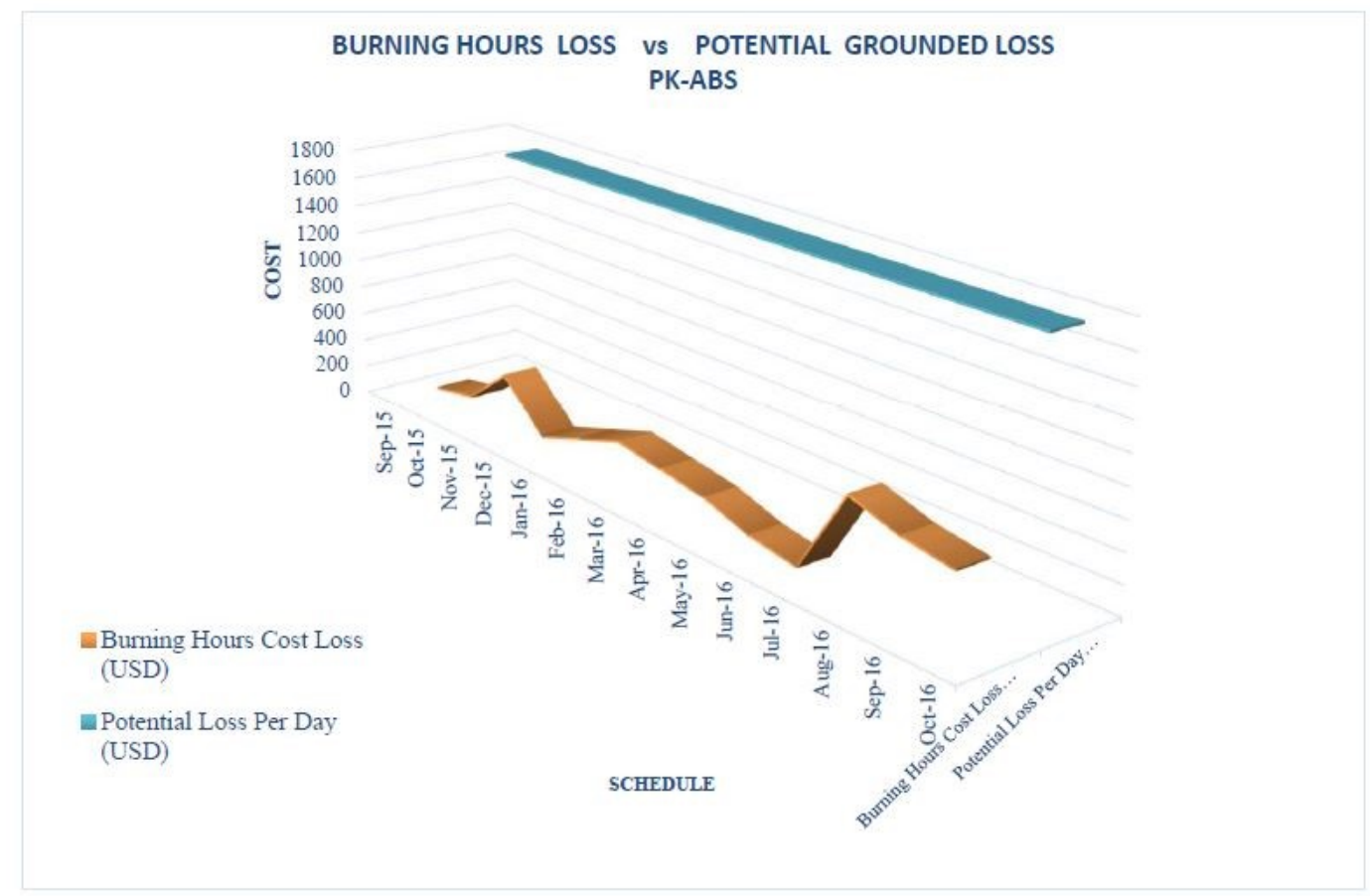

Gambar 1. Grafik data PK-ABS 


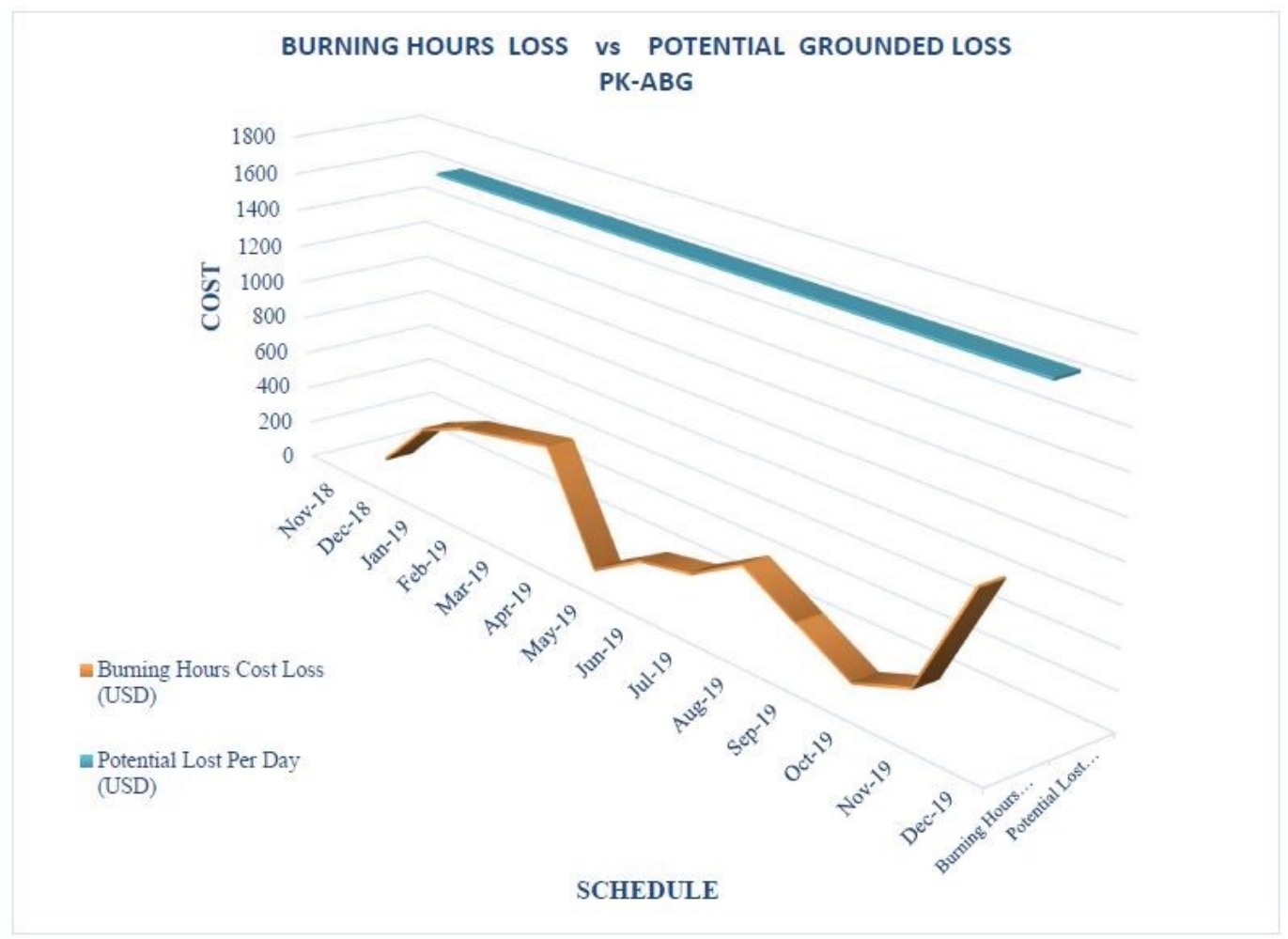

Gambar 2. Grafik Data PK-ABG

Dari gambar 1 dan 2 terlihat bahwa burning hours cost loss yang diperoleh tidak signifikan karena nilainya yang cukup kecil untuk satu kali perawatan. Namun, bila dikalkulasikan dalam satu periode seperti pada penelitian ini, tentunya biaya tersebut cukup signifikan bagi keuangan perusahaan. Maka dari hasil analisis ini, diharapkan adanya koordinasi dan sinergi dari pihak Product Planning operator, serta pihak operation dan bagian - bagian lain dalam kegiatan operasi dan perawatan pesawat, agar kegiatan operasi penerbangan tetap optimal tetapi kegiatan perawatan pesawat tetap bisa dilaksanakan sesuai jadwal dan prosedur yang telah ditentukan.

\section{Kesimpulan}

Berdasarkan hasil pengolahan dan analisa data, maka dapat disimplkan sebagai berikut:

a. Burning Hours adalah efek dari dimajukannya pelaksanaan perawatan pesawat terbang dari jadwal ideal dengan interval manufaktur (125 FH), sehingga terdapar pemakaian jam terbang yang tidak diterbangkan oleh operator. Pada penelitian ini pesawat PK-ABS memiliki total burning hours $81 \mathrm{FH}$, sedangkan untuk pesawat PK-ABG memiliki total burning hours 76 FH. Akibat dari burning hours ini juga berdampak pada kerugian secara tidak langsung terhadap investasi biaya perawatan pesawat terbang sebelumnya yaitu sebesar 4374 USD untuk pesawat PK-ABS, sedangkan untuk PK-ABG sebesar 4104 USD.

b. Untuk meminimalisir dampak dari burning hours maka melaksanakan perawatan pesawat lebih awal dari jadwal seharusnya harus memperhitungkan antara Burning Hours Cost Lost terhadap Potential Loss per day operation.

c. Pelaksanaan perawatan yang lebih awal dari jadwal seharusnya seringkali terjadi dalam kurun waktu tertentu pada setiap operator mengingat penjadwalan perawatan memerlukan kombinasi pertimbangan yang cukup komplek agar pemakaian 
operasional secara optimal tetap tercapai, adapun beberapa pertimbangannnya adalah:

- Ketersediaan supporting hangar slot, manpower, materials, tools dll di jadwal tersebut.

- Hari produktif operasional, harus menghindari grounded dikarenakan kegiatan perawatan pesawat terbang.

- Waktu paling minimal dimajukannya kegiatan perawatan pesawat terbang jika dibandingkan kerugian kesempatan mendapatkan keuntungan mengoperasikan pesawat terbang (Potential Loss per day operation).

\section{DAFTAR PUSTAKA}

[1] Doganis, R (2010) Flying Off Course: Airline Economics and Marketing. Fourth Edition. Routledge, London.

[2] Panca, Anang. (2020, July 13). Retrieved from Harga.web.id: https://harga.web.id/pengertian-dan-klasifikasi-biaya-operasional.info.

[3] Render, Barry \& Ralph M. Stair, Jr. (1997) Quantitative Analysis for Management. Upper Saddle River. New jersey: Prentice-Hall. Inc. 2-3

[4] Viking Air. (2019) PSM 1-63-2 Maintenance Manual Volume 1 DHC-6 Twin Otter Series 300. Viking Air Limited. Kanada

[5] Viking Air (2018) PSM 1-6-7 (IC) - DHC-6 Twin Otter All Series - EMMA Inspection Work Cards. Viking Air Limited. Kanada

[6] V. Junqueira, Viviane Souza, Marcelo S. Nagano, Hugo H. Miyata (2018) Procedure structuring for programming aircraft maintenance activites. Revista de Gestão, 2177-8736 